\title{
Indigenous Initiatives and Information Studies: Unlearning in the Classroom
}

Lisa P. Nathan, University of British Columbia

Amy Perreault, University of British Columbia

\begin{abstract}
This paper provides a classroom-grounded inquiry into Library, Archival, and Information Studies (LAIS) engagement with Indigenous initiatives and issues. We review select diversity-oriented scholarship framed by our interest in LAIS pedagogy. We recognize incisive scholars who have identified pervasive racism and oppression within LAIS, called for change, and envisioned better futures. We contribute to this conversation through reflecting on our attempts to question professional norms in a LAIS classroom, specifically in relation to engagement with Indigenous initiatives. We share our experiences as educators, what we tried, what failed, what we think worked, and why. The paper concludes with our aspirations for diversity initiatives across LAIS education.
\end{abstract}

Keywords: diversity; education; indigenous; information studies; pedagogy

Publication Type: case study

\section{Introduction}

D espite calls for equity, diversity, and inclusion in the fields of library, archival, and information studies (LAIS) in North America, there remains significant room for improvement, particularly when considering library and archival institutions' relationships with Indigenous peoples and communities. In the Canadian context, the term Indigenous refers to Inuit, Métis, and First Nations peoples. ${ }^{1}$ Through this article, we describe our efforts to support diversity within LAIS and outline our experience in designing and facilitating a graduate course entitled "Information Practice \& Protocol in Support of Indigenous Initiatives." We trialed learning tools and course materials, continuously bumping into dominant pedagogical assumptions and approaches (our own and our students). We offer our classroom experiences in hopes that others teaching within information studies degree programs will: a) avoid some of our missteps; b) question the norms they are modeling and enculturating in new cohorts of information professionals; and c) share back lessons related to diversity, disruption, and decolonization that they are learning with their students.

In the following sections we review a selection of writing that informed and inspired our steps towards the enigmatic goal of decolonizing and diversifying LAIS. We are unsure whether library and archives would exist in a "familiar" form if ideals of decolonization and diversity are fully realized, and we elaborate on this in the following section. We, the authors, introduce ourselves and our positions to the course that ground this project. We follow with a brief history of our school's and larger university's involvement in supporting work with and for Inuit, Métis, and First Nations peoples in Canada. The middle of the article introduces central components of the course we worked on during the spring of 2017. Through a thematic analysis, we review our intentions, activities, and considerations for other educators and learners as they negotiate the assemblage of knowledge traditions, histories, government 
policies, and information tools that form societally dominant information system-broadly defined. We discuss the particular challenge of developing skills essential to Indigenous community engagement projects (e.g., the capacity for humility) in a Western academic environment and a profession that work to reinforce practices of acknowledging, engaging with, and holding knowledge that leave little room for alternate ways of doing and knowing. We conclude by offering a conceptual strategy for educators and learners addressing these tensions in and through the LAIS pedagogy.

\section{LAIS Education and Indigenous Knowledge}

Designing learning environments that are responsive to learners' identities and their prior knowledge of Indigenous perspectives and knowledge practices while supporting critical reflection on the assumptions and biases of their professional education is a relatively new endeavor within LAIS pedagogy. Inspiring Indigenous scholars have been calling for this work for decades (e.g., Lawson, 2004; Metoyer-Duran, 1993; Nakata, 2002). We believe strongly that there are ways to support LAIS graduates along this trajectory, whether they identify as Indigenous or settler, to work effectively with Indigenous peoples in support of ongoing developments in Indigenous cultures, languages, governance, legislation, and litigation. Yet, we also acknowledge the paradox embedded in doing this work while firmly situated within colonial structures and practices. As stated by Sensoy and DiAngelo (2014):

An academic course whose primary goal is to challenge social stratification is not without irony. ... [C]ourses are ensconced within an institution whose default effect is the reproduction of inequality. In many ways we are a part of the very system we seek to challenge. Still, we stand in solidarity with others who choose to work within the constraints of academia in order to equip the elite that it produces with perspectives and tools that might ultimately challenge social inequality. (p. 9)

In addition to the paradox of working to decolonize processes and understandings from inside a fundamentally colonial institution (Western academia), we recognize that the "knowledge professions" of libraries, archives, and museums are steeped in colonial assumptions (Dourish \& Mainwaring, 2012, p. 133). The problematic assumptions and biases that inform basic tenets of LIS education are well articulated by Duarte and Belarde-Lewis (2015):

At its most basic, decolonization work is about the divestment of foreign occupying powers from Indigenous homelands, modes of government, ways of caring for the people and living landscapes, and especially ways of thinking. For non-Indigenous individuals decolonization work means stepping back from normative expectations that (1) all knowledge in the world can be represented in document form, (2) to some degree, already is, and (3) Indigenous ways of knowing belong in state-funded university and government library, archive, and museum collections, especially for the benefit of society's privileged elite. ( $p$. 678)

In addition to these broad societal-level critiques, there are also accounts that lay bare the personal costs of maintaining the status quo within the LAIS professions (e.g., Drake, 2017; satifice, 2015). Other scholars give voice to the need for change through insightful theses (e.g., Lawson, 2004), journal articles (e.g., Dali \& Caidi, 2017; Hudson, 2017), books (e.g., Lee \& Kumaran, 2014) and reports (e.g., Carpenter et al., 2017), suggesting a need to disrupt and decolonize the information professions. 
Professional tensions concerning engagement with Indigenous knowledge systems are arguably most prevalent in archival institutions that adhere closely to approaches developed in medieval Europe. As hinted at by Fraser and Todd (2016), if colonial assumptions about how records should (or must) be kept for the future are rejected, is there a place for archival institutions? The authors note that:

To decolonise the archives requires an erasure or negation of the colonial realities of the archives themselves. Given the inherent colonial realities of the archives as institutions, any effort to decolonise or Indigenise the archives in Canada can therefore only ever be partial.

Similar tensions face academic institutions and professional programs such as ours. Although our efforts to decolonize the LAIS classroom may only ever be partial, we remain committed to shifting the parts we can.

\section{Diversity \& LAIS Pedagogy}

The practice of eradicating exclusionary boundaries, lifting glass ceilings, and identifying the confines of the information studies professions has gained some traction through various initiatives and programs internationally. As one example, we point to the American Library Association's Spectrum Scholars Program that "actively recruits and provides scholarships to American Indian/Alaska Native, Asian, Black/African American, Hispanic/Latino, Middle Eastern and North African, and/or Native Hawaiian/Other Pacific Islander students to assist them with obtaining a graduate degree and leadership positions within the profession and ALA" (American Library Association, 2017).

Top down, well-advertised, diversity initiatives are susceptible to the critique that they provide institutional players with something to point to while they continue on with business as usual, relatively unchanged and rarely unsettled. Specifically, we refer the reader to critiques and recommendations outlined in David James Hudson's, “On 'Diversity' as Anti-Racism in Library and Information Studies: A Critique" and Dali and Caidi's, "Diversity by Design", both published in 2017. The authors of these pieces call for more nuanced understandings and negotiations of anti-racism and diversity work within LAIS. They also provide examples of how culture devours policy, an idea that speaks to the ease with which a culture of domination and a desire to maintain the status quo is able to thwart the most progressive diversity policy initiative. In addition, Hudson weaves together an argument that calls out the superficiality of focusing solely on diversity initiatives. He questions whether diversity considerations alone influence real shifts in power dynamics and the politics of difference within the information professions (2017).

Through this article we, the authors and course facilitators, describe a course that aimed to identify and question how power dynamics and difference (Young, 1990) are linked in LAIS professional practice. We attempted to be responsive to the diverse make-up of a LAIS classroom, not only attuned to critical theories where race, history, coloniality, and power are centered, but also open to shifting strategies based on our face-to-face interactions and on the ground moments. We acknowledge the limitations of where we were able to go. In other words, within the space and time in which we are situated, there are limits to knowing and conceptualizing our ideas and shifting the world around us (Young, 1990). We believe that theoretically-informed critical stances are necessary and we work to bring these into the classroom, however we also held space for humanness, affect, and the many manifestations of humility (cultural, intellectual, emotional). In our classroom we reinforce and remake the 
structure both at an individual level and as a group of individuals. Our objective was to enable learners, not just us as educators, to have agency concerning where we ended up.

We also note the irony of the title of our course, "Information Practice and Protocol in Support of Indigenous Initiatives." In our physical location as a class and a cohort of learners, we situate ourselves outside of the Indigenous communities we aim to support even when making connections with initiatives they have identified. Acknowledging limitations and ironies is necessary but cannot be the end point that we reach. In their article, "Diversity by Design," Dali and Caidi (2017) surface the messy reality of doing this work in practice rather than only theorizing about it. The complexity of moving towards decolonizing pedagogy in the classroom requires professional humility on the part of the instructors. It is important to admit that knowledge of appropriate professional practice within an area may be unclear or underdeveloped.

Through the rest of this article we share our experience striving to create a learning community where learners feel challenged but supported enough to continue, and where discomfort was acknowledged as a necessary reality of unlearning biases and "problematic best practices" while coming to know different professional ways of being (Halbert \& Nathan, 2015). We offer this article as a reciprocal gesture. We acknowledge the inspiration we gained from the writing above and offer reflections on our own work for others who teach and learn within this disciplinary context.

\section{Positionality}

Before proceeding we locate ourselves for you, the reader, by describing our positionality as authors of this paper and facilitators of the course described in this paper. Quoting Maher and Tetrault (1993), we use the term positionality to indicate:

$[T]$ hat gender, race, class and other aspects of our identities are markers of relational positions rather than essential qualities. Knowledge is valid when it includes an acknowledgment of the knower's specific position in any context, because changing contextual and relational factors are crucial for defining identities and our knowledge in any given situation. ( p. 118)

We, the two authors of this piece, view our work together from distinctly different vantage points. The first author is a strategist for Indigenous engagement in teaching, learning, and technology initiatives and a recent Master of Library and Information Studies (MLIS) graduate, who comes from Métis heritage. The second author is a settler scholar and instructor in LAIS who also serves as the coordinator of her school's First Nations Curriculum Concentration (FNCC). Our collaboration grew out of conversations concerning the need to connect critical theory with reflective practice. The first author drew upon experiences in other courses and her insights as strategist for Indigenous engagement to advise and support the second author, who was the official course instructor.

In order to locate ourselves, our work, our teaching, and our learning context, we would like to acknowledge that we have the privilege of doing so on the unceded, ancestral and traditional lands of the hən'q'əmin'əm' speaking $\mathrm{x}^{\mathrm{w}} \mathrm{m} ə \theta \mathrm{k} \mathrm{k}^{\mathrm{w}} \partial \mathrm{y}^{\prime} ə \mathrm{~m}$ (Musqueam) people. ${ }^{2}$ Our institution, the University of British Columbia (UBC), is located adjacent to the Musqueam Indian Reserve, a small parcel of land allocated to members of this community through racist policies such as the Indian Act, ${ }^{3}$ and the unlawful encroachment of traditional territories by non-Indigenous settlement. The leadership, guidance, and groundwork undertaken by members of Musqueam at the university created a foundation where discussions of Indigenous issues in the classroom 
are now possible. The acknowledgement and continuous identification of doing our work on unceded, ancestral, and traditional lands reminds us (and other learners) not only of the current relationship between Musqueam and UBC but also of the current state of relations between the state and many Indigenous communities where land rights continue to be contested and fought for.

\section{First Nations Curriculum Concentration}

The FNCC is available as an area of specialization to students in the Masters of Library and Information Studies (MLIS) program, the Masters of Archival Studies (MAS) program, and those who are working towards both degrees in the Dual program offered by the School of Library, Archival, and Information Studies (SLAIS). The original proposal for the FNCC at SLAIS was developed in 1996. The concentration was first offered to students in 1998. In early marketing material, the concentration was described as an initiative informed by the school's Admissions and Adjudication Committee in consultation with staff from UBC's First Nations Longhouse. A copy of the print literature available through the school's admissions office in 1998 describes the motivation behind the concentration:

. . . to serve the educational needs of First Nations individuals to work effectively in libraries and archives, both within and outside native communities. First Nations people must increasingly deal with inter-related library, archival and museum materials in developing and providing library and archival service to First Nations communities, in support of treaty negotiations and litigation, in the preservation of culture and languages, and in preparation for self-government. Consequently, First Nations people who wish to pursue a career as an information provider should consider this graduate program in library and archival studies, which takes into account a knowledge and understanding of First Nations cultural traditions. (SLAIS, 1998, p. 2)

Soon after, the concentration was developed at SLAIS, UBC implemented a university-wide strategic plan prioritizing Indigenous initiatives. The development of the Aboriginal Strategic Plan (ASP) acknowledged the existence of Indigenous curriculum within focused areas and programs, however it called for the development of more offerings that spanned across disciplines, departments, and faculties:

Although some departments already lead in the development of comprehensive and sophisticated understandings of Aboriginal issues and perspectives, that responsibility cannot be limited to those units. Efforts must be well supported to ensure that those understandings are well represented across the curriculum and that instructional practices reflect the reality of a multicultural student body that includes Aboriginal students. An ongoing venue that allows for exchange of information and ideas for the development of Aboriginal curricula across departments, disciplines, and faculties should be established. (UBC Aboriginal Strategic Plan, 2008, p. 10)

In reflecting on the history of support for First Nations and Indigenous individuals through the development of the FNCC, SLAIS predated the larger institution's initiatives. However, as the ASP identifies, the bridging of curriculum that focused on areas related to Indigenous community engagement, and the skills necessary to do this work are still primarily limited to distinct specialized courses (or in the case of SLAIS a distinct concentration) rather than embedded across the curriculum. Additionally, the FNCC was originally framed as being for 
First Nations individuals, although in the past seven years the concentration has shifted to become more relevant to Indigenous peoples and settlers more broadly.

\section{The Course}

Twelve years post-ASP, the course offering we introduce in this section still fits the description of a distinct specialized course as is evident from its title, "Information Practices in Support of Indigenous Initiatives." This class was first available to SLAIS students in 2012. The goal of the course is:

[To] prepare students to work effectively with Indigenous peoples in support of ongoing developments in Indigenous culture, languages, governance, legislation and litigation. Students will critically engage with the assemblage of knowledge traditions, histories, government policies, and information tools that form societally dominant, information systems. Students will develop their ability to listen, capacity for humility and strategies to work through tensions that develop when dominant information management practices do not support the interests of Indigenous peoples. At the end of the course, students will be well positioned to undertake experiential learning opportunities with Indigenousoriented organizations, including but not limited to libraries, archives and cultural centres. $^{4}$

The first year it was officially offered, 9 masters students enrolled in the MLIS course. Since that time, enrollment each year has been between 20-26 masters students (MLIS, MAS and Dual). Learners who sign up for this course are from the larger school population, thus they represent the larger school's demographics. The majority of students identify as female and a large number of the students are Canadian, although approximately thirty percent are American. A small percentage come from other countries in the world. In the course we reflect upon in this paper, students identified as non-Indigenous and Indigenous. Some had extensive knowledge of Indigenous community initiatives through familial connections and lived experiences or through their involvement with Indigenous organizations. Some learners had experience thinking with a social justice lens, some were participating in the FNCC, and a few simply had an interest in a course with an Indigenous emphasis.

\section{Methodology, Evidence, \& Analysis}

The focus of our project was to consider the effectiveness of our pedagogical approaches, learning tools, and course materials that we designed or adapted to prepare students to work effectively with Indigenous peoples in support of ongoing developments in Indigenous culture, languages, governance, legislation, and litigation. Based on one author's past experience of writing about pedagogical practice (Halbert \& Nathan, 2015), we were skeptical that we could be sure that asking students for permission to include their thoughts and work would not be experienced as coercive on some level. Instead, we decided to draw upon our own reflections based on our design, teaching, and assessment of the class rather than mining the labor of our students. We did not ask students for permission to use their direct quotes or samples of their work.

Our analytic process was iterative as both our insights and our humility as educators developed throughout the course. Our pedagogical practice included developing an iterative planning and reflection process that we followed each week. This included a series of prompts that guided our preparations for each class and guided our reflections directly after class. We shared reflective writing with each other either before or during our weekly face-to-face planning 
meetings. During these meetings, we deliberated on assigned materials (readings, videos, etc.), classroom activities, and class-wide discussions to determine what went well and what did not seem to land well with students. We also returned to a template of prompts mentioned above that helped us identify what worked and why, with explicit attention to the affective domains of the course and whether our design supported these aspects adequately. After the course was complete, we conducted a thematic analysis of our notes (Terry et al., 2017). In addition to helping us improve future iterations of the class itself, we hoped to use this analysis to frame a realistic and approachable piece of scholarship that others might find useful as they navigate their own pathways to diversify the LAIS classroom.

\section{Themes}

The following section is divided into four areas of tension that we identified and attempted to address throughout the term. The specific thematic labels were decided upon as we reviewed our notes from pre-class planning, creating assignments, facilitating class activities, post-class reflections, and reflective conversations throughout the term. The themes are: Positionality Awareness, Prior Knowledge \& Unlearning, Reflective Practice, and Cultivating Humility. Although intertwined in many ways, in the following sections we discuss each area in turn. Each begins with our intentions related to the particular topic that we developed in conversation with each other based on our previous facilitation experiences, scholarship, and learning from our Indigenous and non-Indigenous colleagues. The descriptions of our intentions are followed by example materials and/or activities we developed to engage students in that area and concludes with considerations of what we learned as educators from these attempts.

\section{Positionality Awareness}

\section{Intentions}

To create a learning community that was aware and supportive of the different positionalities and experiences in the room, we introduced an activity on the first day of class that complicated dominant ideas of classroom guidelines. Our intention was twofold. First, we wanted to invite students to question their understandings of the space and draw a critical eye to the notion of a "safe" classroom and the paradoxes this will inevitably create (Barrett, 2010; Holley \& Steiner, 2005; Redmond, 2010). Second, we wanted to collectively discuss and cocreate our classroom guidelines. This included a discussion of ways that, as a learning community, we could hold each other up but also hold each other accountable, each of us contributing as well as receiving information and knowledge. We respectfully acknowledge that this concept is centered within the Centre for Critical Indigenous Studies at our institution. ${ }^{5}$

The idea of holding each other up while holding each other accountable has particular value within our context because of its grounding in accountability, responsibility for the communities we serve, for one another, and for our own action. This grounding and approach echoes critical pedagogy scholars' approaches to safe space where positionality is central and discomfort is acknowledged as part of the learning process (e.g., The Roestone Collective, 2014). It asks students to continue even though the questions they will be asked may cause discomfort or challenge what they know (Justice, 2014). Our intention was not to give a prescriptive set of rules or checklists of proper behavior as this would be unproductive for the realities that learners would encounter in their careers. Rather, we hoped to draw on learners' past experiences where their positionality and values may have been challenged or shifted and how, as a class, we could set an intention for ways to do this, but in a way that is productive for all of those in our learning community. 


\section{Activities}

Drawing on an article by Sensoy \& DiAngelo (2014) titled "Respect differences? Challenging the common guidelines in social justice education," we asked learners to form small groups where they were assigned one of the aspirational phrases in Figure 1.

- Strive for intellectual humility. Be willing to grapple with challenging ideas.

- Differentiate between opinion-which everyone has-and informed knowledge, which comes from sustained experience, study, and practice. Hold your opinions lightly and with humility.

- Let go of personal anecdotal evidence and look at broader group-level patterns.

- Notice your own defensive reactions and attempt to use these reactions as entry points for gaining deeper self-knowledge, rather than as a rationale for closing off.

- Recognize how your own social positionality (e.g., race, class, gender, sexuality, ability) informs your perspectives and reactions to your instructor and those whose work you study in the course.

- Differentiate between safety and comfort. Accept discomfort as necessary for social justice growth.

- Identify where your learning edge is and push it. For example, whenever you think, I already know this, ask yourself, 'How can I take this deeper?' Or, 'How am I applying in practice what I already know?'

Figure 1. Positionality Awareness Prompts

Learners were challenged to consider the phrase and develop examples of what the aspiration looked like (drawing on their experiences) or might look like in practice.

After the breakout, groups reported back on their conversations and we led a full class discussion on the phrases. It became apparent that concepts of positionality and intersectionality were new considerations for a number of students in the class. During our post-class debrief, we identified related areas for further focus including:

- Feeling daunted: some felt ill-equipped to engage meaningfully and respectfully.

- Fear of exhaustion: some expressed a fear of getting burnt out-due to the heavy nature of the material.

- Wary of paralysis: Students identified that they did not want concern over missteps to take over the class and stall engagement and learning.

- Identifying problematic equivalencies: Students had a tendency to suggest that the class incorporate rules from other social justice work they knew about (e.g., suggesting frameworks and practices they were familiar with) and struggled with the idea that procedures from other social justice contexts (e.g., refugee rights, mental health advocacy, gender and sexuality initiatives) might not transfer well and have important distinctions from work related to colonialism and Indigenous communities' relationships and experiences with the state. 
We acknowledged students' concerns, particularly those about "making mistakes." We were keen to create spaces where learners felt comfortable enough to be able to ask questions while ideas were being tested out and formed. In our context, this space is valuable to create a bridge to accountability and action, as a large portion of the class learners may not feel they have a right to speak to Indigenous concerns as non-Indigenous people, or they might be nervous to say the wrong thing or unintentionally offend their peers. This prompted us to explore the concept of anonymity in our learning design.

We trialed two other activities in our efforts to contribute to students' reflections on positionality while also providing a level of anonymity (and/or privacy). In order to assess the course and learning climate that we were working within, we set up a "Padlet" (padlet.com) where students could anonymously answer the following questions:

- What is working well for you in the class in terms of your learning?

- Is there a particular topic (or question or position article or...) that you would like to make space to discuss?

- Is there anything the instructor can do to improve your learning for this class?

Everyone in the class was invited to consider their colleagues' anonymous responses. We observed that learners were interested to learn what their classmates thought and how they responded to these questions. We found that anonymity provided to students by the Padlet platform provided an environment where educators could gain feedback on what is working and what they might consider moving forward. Students were also supported in thinking about their own position to the course in relation to their colleagues' shared reflections about the course.

The second type of activity we tried was more directly tied to considerations of positionality. We developed a series of activities inspired by a diversity statement written by Dr. Natalie Baloy. ${ }^{6}$ Dr. Baloy gave us permission to use her statement for the activity. We introduced the activity by providing learners with a print version of Baloy's one-page statement reflecting on her positionality and how her positionality has influenced her education and career. Small groups of students discussed the statement after a close reading. After fifteen minutes of small group discussion, the full class gathered to discuss strengths of the statement and areas that may or may not work in different contexts. In each of the class sessions that followed we included one short writing prompt and provided learners with a short time (less than five minutes) to write a response in class. Through these prompts students were encouraged to reflect on their positionality as individuals, as learners, and as future professionals. The writing activities took place with everyone working quietly in the classroom, and, after each activity, learners placed their reflections in a personalized folder that we held for them from week to week. At the end of the course learners were encouraged to collate their various pieces of writing into their positionality statements on which they could draw upon in the future (e.g., as part of job application material). The short writing responses and the final draft statements were not read or graded by the authors.

\section{Considerations}

Through the use of lightweight, anonymity-supporting collaborative tools (e.g., padlet.com), and weekly, non-graded, reflective writing prompts, we held space for students to gather their thoughts anonymously (and sometimes privately) as they processed information in relation to their own positionality. Building on what we learned through these activities and throughout the term, we circled back to the topic of positionality awareness. We stressed that there is no 
end point related to one's positionality awareness. For each of us, our positionality is continually shifting as we and our environments change and shift throughout our lives (JohnsonBailey \& Cervero, 1998). The classroom is not absent of the societal, historical, and geographic layers where it is embedded. This is particularly key to acknowledge in a space where the ways ideas are shared and perceptions shift are influenced by our individual positionalities (Tsukada \& Perreault, 2016). There is a need to help students develop the capacity to critically engage with questions of who they are and where they come from, honor the pedagogy of territorial teachings (in our context as shared by members of Musqueam), and articulate their positionality when engaging with Indigenous communities in the future.

\section{Prior Knowledge and Unlearning}

\section{Intentions}

When developing the course, we hoped to contribute to learners' knowledge of Indigenous history and contemporary issues while also helping them to question and potentially unlearn particular professional assumptions and biases. We use the term unlearn to refer to questioning and potentially rejecting what has been learned in the past when understandings are found to be incorrect, with the goal of not perpetuating problematic and harmful understandings (e.g., racial, gender-based, cultural bias, or stereotypes). We posit that unlearning takes a great deal of effort; Warrell (2014) compares it to the onerous labor of stripping paint:

Unlearning is about moving away from something-letting go-rather than acquiring. It's like stripping old paint. It lays the foundation for the new layer of fresh learning to be acquired and to stick. But like the painter who needs to prepare a surface, stripping the paint is $70 \%$ of the work while repainting is only $30 \%$.

Early in the term we asked students to reflect on what they had been taught about Indigenous issues and perspectives and what areas they felt they knew little about. It became clear in these moments that there was genuine concern about a lack of knowledge, an interest in learning more about Indigenous initiatives, and a desire to unlearn problematic biases and assumptions.

\section{Activities}

The reading materials assigned to students for the second week of the course focused on past federal policies that impacted Indigenous communities. Many of these resources focused on policies that are well known within fields such as Indigenous Studies. However, it became apparent in the discussions following these assigned readings that there were significant knowledge gaps in this area due to a lack of exposure to this information during the students' previous education (formal and informal). As educators, we struggled with questions of how much time we should even spend in a graduate program introducing students to the basic history of settler initiatives in Canada. In addition to these prior knowledge gaps, our class was made up of a large number of American students who lacked much of the Canadian context and did not understand the differences and similarities between the way the nation state of Canada interacts with Indigenous communities and individuals, and the way the nation state of the US interacts with Indigenous communities and individuals.

Co-existing with these gaps in prior knowledge were problematic norms and values. Throughout their graduate degree program, these students were instructed to learn "best-practices" and values that have historically been central to a profession where helping and being in service to 
others is integral to the core skills of what you should know, do, and practice. The helping narrative, that part of being a professional is knowing what help is needed, bumps up against some of the ideas we wanted to critically engage with, and in some ways is counterintuitive to the concept of professional and intellectual humility.

\section{Considerations}

Even after the course was completed we were still debating ways to address both a lack of knowledge and the need to unlearn. A few months later, Musqueam Senior Archivist and settler Jason Woolman addressed these intertwined issues in an awards acceptance speech. He was accepting our school's alumni award and speaking to a roomful of LAIS educators, learners, and practitioners. In a few short lines, Woolman (2017) spoke to the issues of being a "professional" while lacking adequate prior knowledge, acknowledging "what you don't know," and the need to unlearn:

In fact, I have spent much of my time at Musqueam "unlearning." Librarians and archivists, and those in the information profession strive to be objective but we all come prepared with our own personal and professional biases, and epistemologies to unpack.

The first few teachings I received at Musqueam were to acknowledge what you don't know (which is an awful lot as was apparent) and that there are no shortcuts. Our degrees prove, if nothing else, we have the ability to learn. The first thing we must do is to acknowledge that learning is life long and that we operate in a myriad of intersecting juridical systems. Musqueam's culture is millennia old - it hasn't been supplanted by the Canadian system, but it does have intersections with it. The various roles and responsibilities I have been fortunate enough to take on reflect the responsibilities that come with caring for this knowledge.

In future iterations of this course, Jason Woolman's reflections will be introduced early in the course both to draw on locally grounded perspectives and to provide the learning community with language for speaking about unlearning and the problems of inadequate and problematic prior knowledge and assumptions.

\section{Reflective Practice}

\section{Intentions}

The way that this course is situated within our school's MLIS program it is likely to be among the last courses a student takes before graduation. Courses that cover Indigenous issues and initiatives are not required for graduation or mentioned in job postings. Yet, this course introduces concepts and challenges dominant approaches in ways that complicates ideas (e.g., "open access" as a universal good) that students have been learning throughout their program of study. This experience of disruption towards the end of a student's program contributes to the complexity of design and delivery of the course. From previous iterations of the course we knew that it can be jarring for burgeoning professionals to be asked to reflect on and question their new profession's practices and norms. This experience may impact their learning if it is not directly acknowledged and supported as part of the overall learning design. Thus, we aspired to design opportunities for students to develop their capacity for reflective practice, demonstrating the utility of critical reflection as making space for change within professional practice. 


\section{Activities}

As the course progressed, learners began to read about institutional and structural barriers within information organizations (e.g., Lawson, 2004; Duarte \& Belarde-Lewis, 2015). We asked them to apply their understandings of these barriers as part of a series of "Problematic Situations." This assignment draws on real life scenarios shared by local information professionals (described more thoroughly in Halbert \& Nathan, 2015). These scenarios reveal ways that dominant information practices, particularly within information institutions, are harmful to Indigenous peoples. Six times during the term students were asked to read, reflect on, and respond to a different problematic scenario. Sometimes they completed this activity alone and sometimes in small groups. Students were asked to articulate the issues they thought were related to the scenario and to strategize a possible solution or way forward.

\section{Considerations}

As they engaged the problematic situations, learners' reflections revealed the prevalence of structural, institutional, and legal constraints (e.g., knowledge organization schemes, workplace dynamics, juridical systems, and copyright law) that made some situations unresolvable in the short term. It was at this point that the first author introduced a framework (Nathan, Thieme, \& Tatar, 2017) to guide students' reflective practice when confronted with nuanced and complicated situations. The framework identifies and describes three types of tensions: disruptions, dilemmas, and paradoxes. We propose that these three tensions are generative for helping learners gain perspective and insight through their reflective practice. A disruption in this case would be a scenario that challenges accepted norms of what constitutes "ethically informed" LAIS practice. To overcome these concerns the students would need to broaden what counts as ethical professional practice, but they are able to do this work and see what needs to be broadened (e.g., an archive respecting a First Nation community's requests regarding care for particular items or belongings). A dilemma is an unsettling situation that may not be immediately resolvable and next steps are unclear. Students may be able to imagine solutions that might exist in the future, but at this point, a solution does not appear to be immediately resolvable (e.g., an archive holds the only school photos of Indian Residential School survivors).

The last category of tension is a paradox, situations that do not have a single correct answer, nor can those involved envision what a potential solution might look like (e.g., developing policies that respect the records of individuals from myriad juridical systems, collected by the Truth and Reconciliation Commission, ${ }^{7}$ and now controlled by a federal government institution). Situations that hold contradictory qualities are paradoxes. In talking through this framework, we also acknowledged the limitations of one's own positionality. We are always limited in our knowledge. We proposed that learners draw upon the disruption, dilemma, and paradox model as they processed their responses to the problematic situations by asking the following questions:

\section{What can I do now?}

2. What can I bring forward for further consideration?

3. What are the structural issues?

4. What are the big picture issues that need more time, resources, and people?

Leveraging these questions and the disruption, dilemma, and paradox framings, students identified ways that thoughtful reflective practice can help them engage, if not resolve, 
difficult situations.

\section{Capacity for Humility}

\section{Intentions}

At the beginning of the class one of the enduring understandings we hoped would be part of the course was the importance of humility. The consideration of humility in a postsecondary classroom comes out of observations within communities where we have witnessed a lack of humility. Lack of humility can be detrimental to relationships between information professionals and the communities they intend to work with and support. We approached this objective with hesitation because of our location external to community and within an expert venerating environment (highly ranked research university). We also questioned how humility could be assessed, if at all, and whether it was even our role to do so.

\section{Activities}

In our class readings and materials, we assigned readings and videos on cultural and professional humility, but at the end of the course we were not sure if this landed with students.

Throughout the term we used index cards as a lightweight, non-digital (no surveillance) feedback mechanism where we gathered students' questions around various topics, such as background knowledge and questions relating to Indigenous perspectives, positions, and contemporary contexts. We decided to try using an index card activity on the last day of class as a reflective summative exercise. As part of this activity we asked students to reflect on the following questions:

1. What is something you have contributed to the learning community?

2. What is something you have received? They wrote out their responses and placed them individually in a bowl that was passed around the room. They were not asked to share their reflections aloud.

This activity models concepts of reflection and reciprocity and asks learners to pause and articulate how their learning has been informed both by their own actions as well as by the actions of others. It also counters the idea that knowledge is simply consumable and does not need to be regenerated. In this class, the activities supported the concept of reciprocity and regeneration by asking students to contribute to the learning community they were part of. Overwhelmingly the reflections identified intellectual, professional, and cultural humility as key things that students learned about and will carry forward with them.

In part, students came to this class with a variety of interests and intentions so we could predict that the outcome of the course would mirror this. However, what we learned is that the intentions to learn, both about the course materials and the different perspectives of their classmates in addition to learning about themselves, is an endeavour that students embraced and reflected on as part of their deep learning and humility.

\section{Considerations}

In her article, "Working a Third Space: Indigenous Knowledge in the Post Colonial University," Haig-Brown (2008) shares her experience teaching at a Canadian university where, as a settler scholar, she offers her reflections on a way of thinking about the intersection of knowledge 
systems within her discipline where there are "contesting ontologies and epistemologies" and through these intersections, collisions, and interruptions there exists the potential of creating new ways of thinking (p. 260). Similarly, North American libraries, archives, and other 'knowledge holding' institutions (including academia) have historically been a space where middle-class, white-centered, and well-intentioned views have dominated activities and approaches (Dourish \& Mainwaring, 2012). There is a long-standing tendency to frame library, archival, and museum policies and practices as neutral, when they continue to have a decidedly negative impact on Indigenous peoples (Lawson, 2004).

As mentioned earlier, cultural, professional, and intellectual humility were key skills that students identified were integral to their learning process within this course. For many, this was the first class in their LAIS program where they were asked to consider their own positionality as well as the positionality of their discipline and the complicity of it within the larger colonial project in Canada. For others, this was the first time that they had a dedicated amount of time and space to think in depth about Indigenous community experiences and ways that these are shaping the future directions of LAIS practices. In addition to Indigenous knowledge systems, histories, and perspectives, students also had opportunities to refine their interpersonal skills. In instances when navigating complex scenarios presented moments where values, belief systems, past experiences, and lived realities conflicted, as a result interpersonal skills needed to be tapped into in order to foster a classroom climate where students could hold space for each other. Students often articulated feelings of humility as they worked to develop recommendations for situations in a less than ideal world.

\section{Conclusion}

Through shifts and adaptations to the design of the course, we worked towards a responsive learning environment where students took steps refining and developing skills that are critical for the work they will encounter once they graduate, such as positionality, questioning their prior learning, reflective practice, and capacity for humility. We attempted to model (i.e., provide examples of) strategies for working through tensions that develop when dominant information management practices do not support the interests of Indigenous peoples. Throughout the course, we drew students' attention to the likelihood that after the course is finished they would have more questions than when they started. Through an enhanced understanding of the importance of asking difficult questions, we assert that graduates will be better positioned to work with Indigenous communities. They will recognize the significance of approaching relationships with others ready to listen and learn, rather than assume that their knowledge of LAIS principles and skill sets will be applicable to any situation. To quote from Musqueam Senior Archivist Jason Woolman (2017) again,

At Musqueam I have been blessed to unlearn, and relearn various ways of seeing the world, and understanding the relationships that tie us together. And relationships are key. We don't operate in a vacuum. It is incumbent upon us to develop relationships with our respective communities.

Through this paper, we attempt to model some of the skills we addressed in the classroom. We introduced ourselves and our positions to the course offering that grounds this project. We provided a brief history of our school's and larger university's involvement in supporting work with and for Indigenous peoples. Through a thematic analysis, we reviewed particular activities and materials that show promise for other educators who wish to support learners as they engage with the assemblage of knowledge traditions, histories, government policies, and information tools that form societally dominant information systems-broadly defined. We discuss skills that we assert are essential to Indigenous community engagement projects.

The International Journal of Information, Diversity, \& Inclusion, 2(1-2), 2018

ISSN 2574-3430, publish.lib.umd.edu/IJIDI/ 
Specifically, we focus on positionality awareness, acknowledging the need to unlearn and ask critical questions, reflective practice, and the capacity for humility. These are particularly important within a Western academic environment and a profession that work to reinforce practices of acknowledging, engaging with, and holding knowledge that leave little room for alternate ways of knowing.

We assert that the influence of this kind of learning deepens the more we return to it through shifts to institutional culture, program outcomes, and course objectives. Embedding diversity into a school's culture, centering it even though it may be unsettling, and making it an integral part of what graduates take with them into their next endeavors is not the same as a top-down diversity initiative that provides money to some, while leaving problematic structures and practices unquestioned. It is the longer-term conceptual strategy we offer for educators and learners to better address ongoing tensions and bias, integrate Indigenous content throughout your core classes, and reflect knowledge of it in your graduate competencies. We need to move away from initiatives that frame respectful engagement with Indigenous knowledge systems as an "add-on" specialization or elective course. These skills and competencies are essential for all LAIS professionals.

In Canada we are witnessing an overall growth in the general public's awareness of and interest in Indigenous histories, contexts, and lived realities through events such as the Truth and Reconciliation Commission (e.g., Truth and Reconciliation Commission of Canada, 2015), longstanding and multifaceted relationships to land being acknowledged (e.g., Rossiter \& Burke Wood, 2017), the occupation of unceded land being acknowledged by government leaders (e.g., Hunter, 2017), and Supreme Court cases acknowledging the rights of Indigenous peoples to control their records (e.g., Canada (Attorney General) v. Fontaine, 2017 SCC 47, 2107). The increase in demand to equip LAIS graduates with skills that will be useful to the Indigenous peoples they work with comes as a result of the time we are in and the countless initiatives led by Indigenous peoples. As community led and initiated projects increase, so does the need for adequately equipped informational professionals. We assert that North American schools of library and information studies support the faculty who will guide these learners. Yet, instructors may not feel they have the training and education needed to engage with Indigenous history and ongoing initiatives. We put forward that these dynamics underpin and have historically steered the outcome away from more integration of Indigenous perspectives within and across curricular offerings.

A reviewer of this paper asked, "Is this about sharing your experiences teaching this class in this context - and advancing the state of Indigenous issues in LIS education? Or, is it about offering suggestions for educators in OTHER contexts to advance their ability . . ." We suspect that it is the positionality of the reader that will be the biggest determinant of whether either or both of these goals are generative for their situation and whether this paper helps them take steps towards their goal. We reiterate the quote on positionality from Section 4, "Knowledge is valid when it includes an acknowledgment of the knower's specific position in any context, because changing contextual and relational factors are crucial for defining identities and our knowledge in any given situation" (Maher \& Tetreault, 1993, p. 118).

The creation of a body of research and scholarship in the area of Indigenous curricular design and implementation contributes to the growing need for accessible examples that others who teach in classrooms within LAIS programs can draw upon and develop further. As this field of pedagogical inquiry expands, we hope that through examining our practice and revisiting forces that inform it (e.g., race, power structures, colonial legacies, and contradictory paradigms) we can create more spaces where these issues can be articulated and addressed. 


\section{Acknowledgements}

Throughout this article and this experience more broadly, we have had the privilege to be guided by the knowledge and wisdom of several individuals as well as a collective of learners, colleagues, and educators. We thank them. We reiterate our gratitude to the Musqueam community who have shared their traditional and ancestral space of learning with us, allowing us to make mistakes and humbly return to them in order to build on skills that might be useful in the future.

\section{Endnotes}

\footnotetext{
1 “'First Nation'” is a term used to describe Aboriginal peoples of Canada who are ethnically neither Métis nor Inuit. This term came into common usage in the 1970s and " 80 s and generally replaced the term 'Indian,' although unlike "Indian," the term "First Nation" does not have a legal definition ("First Nations," n.d.).

2 http: / / www. musqueam.bc.ca

3 "The Indian Act is a Canadian federal law that governs in matters pertaining to Indian status, bands, and Indian reserves. Throughout history it has been highly invasive and paternalistic, as it authorizes the Canadian federal government to regulate and administer in the affairs and day-to-day lives of registered Indians and reserve communities. The Indian Act has also enabled the government to determine the land base of these groups in the form of reserves, and even to define who qualifies as Indian in the form of Indian status" ("The Indian Act," para. 2). ${ }^{4}$ http://slais.ubc.ca/libr569a/

5 https: / / fnis.arts.ubc.ca/community/institute-for-critical-indigenous-studies/

6 http: / / www.academia.edu/10712366/Diversity_Statement

7 "The Truth and Reconciliation Commission (TRC) was established to gather testimony and records surrounding the Indian Residential School system that operated in Canada from 1875 [to] 1996. Generations of Aboriginal children were forcibly taken from their families and communities and placed in the schools, where many suffered significant abuse and many died" (Ward, 2014, para. 3). "The Truth and Reconciliation Commission of Canada was established in 2008 in a settlement agreement that derived from the largest class-action suit in Canadian history. The Commission's mandate is to gather testimony from survivors, gather materials documenting the schools and policies that produced them, and establish means to further educate and inform Canadians about the schools, their history, and their effects, with the intent of contributing to a reconciliation between Aboriginal people and wider Canadian society" ("Purpose," para. 1-2).

To learn more about the Indian Residential School System in Canada, visit http://indigenousfoundations.web.arts.ubc.ca/the_residential_school_system/.
}

\section{References}

American Library Association. (2017). Spectrum scholarship program. Retrieved from http://www.ala.org/advocacy/spectrum

Baloy, Natalie J. K. (n.d.) Diversity Statement. Retrieved from http://www.academia.edu/10712366/Diversity_Statement

Barrett, B. J. (2010). Is "safety" dangerous? A critical examination of the classroom as safe space. The Canadian Journal for the Scholarship of Teaching and Learning, 1(1). 
Canada (Attorney General) v. Fontaine, 2017 SCC 47, No. 37037 (SCC, 2017). Retrieved from https://scc-csc.lexum.com/scc-csc/scc-csc/en/16797/1/document.do

Carpenter, J., Guerin, A., Kaczmarek, M., Lawson, G., Lawson, K., Nathan, L. P., \& Turin, M. (2017). Digital access for language and culture in First Nations communities. Retrieved from http: //heiltsuk.arts.ubc.ca/report/

Dali, K., \& Caidi, N. (2017). Diversity by design. The Library Quarterly, 87(2), 88-98.

Dourish, P., \& Mainwaring, S. D. (2012). Ubicomp's colonial impulse. Ubicomp'12 - Proceedings of the 2012 ACM Conference On Ubiquitous Computing, Pittsburgh, PA, 133-142.

Drake, J. M. (2017, June 26). I'm leaving the archival profession: It's better this way. Medium. Retrieved from https: / /medium.com/on-archivy/im-leaving-the-archival-profession-its-better-this-way-ed631c6d72fe

Duarte, M. E., \& Belarde-Lewis, M. (2015). Imagining: Creating spaces for Indigenous ontologies. Cataloging \& Classification Quarterly, 53(5-6), 677-702.

First Nations. (n.d.). Retrieved from http://indigenousfoundations.web.arts.ubc.ca/terminology/

Fraser, C., \& Todd, Z. (2016, February 16). Decolonial sensibilities: Indigenous research and engaging with archives in contemporary colonial Canada. Internationale Online. Retrieved from http://www.internationaleonline.org/research/decolonising_practices/54_decolonial_s ensibilities_indigenous_research_and_engaging_with_archives_in_contemporary_coloni al_canada

Haig-Brown, C. (2008). Working a third space: Indigenous knowledge in the post/colonial university. Canadian Journal of Native Education, 31(1), 253-267.

Halbert, H. \& \& Nathan, L. P. (2015). Designing for discomfort: Supporting critical reflection through interactive tools. Proceedings of the 18th ACM Conference on Computer Supported Cooperative Work \& Social Computing (CSCW'15), Vancouver, BC, 349-360.

Holley, L. C., \& Steiner, S. (2005). Safe space: Student perspectives on classroom environment. Journal of Social Work Education, 41(1), 49-64.

Hudson, D. J. (2017). On "Diversity" as anti-racism in library and information studies: A critique. Journal of Critical Library and Information Studies, 1(1).

Hunter, J. (2017, October 22). Horgan's acknowledgment of unceded Indigenous territory a milestone for B.C. The Globe and Mail. Retrieved from https: / / www.theglobeandmail.com/news/british-columbia/horgans-acknowledgmentof-bcs-unceded-territory-part-of-a-path-forward/article36686705/

The Indian Act. (n.d.). Retrieved from http://indigenousfoundations.web.arts.ubc.ca/the_indian_act/

Johnson-Bailey, J., \& Cervero, R. M. (1998). Power dynamics in teaching and learning practices: An examination of two adult education classrooms. International Journal of Lifelong Education, 17(6), 389-399. 
Justice, D. H. (2014) No truth, no reconciliation. The Raven. Retrieved from https://issuu.com/firstnationsindigenousstudies/docs/fnsp_newsletter_2014_singlepag $\underline{\mathrm{e}}$

Lawson, K. L. (2004). Precious fragments: First Nations materials in archives, libraries and museums. (Master's thesis). University of British Columbia. Retrieved from https://open.library.ubc.ca/clRcle/collections/ubctheses/831/items/1.0091657

Lee, D., \& Kumaran, M. (Eds.). (2014). Aboriginal and visible minority librarians: Oral histories from Canada. Lanham, Maryland: Rowman \& Littlefield.

Maher, F. A., \& Tetreault, M. K. (1993). Frames of positionality: Constructing meaningful dialogues about gender and race. Anthropological Quarterly, 66(3), 118-126.

Metoyer-Duran, C. (1993). Gatekeepers in ethnolinguistic communities. Norwood, N.J.: Ablex.

Nakata, M. (2002). Indigenous knowledge and the cultural interface: Underlying issues at the intersection of knowledge and information systems. IFLA Journal, 28(5-6), 281-291.

Nathan, L.P., Thieme, A, Branham, S., \& Tatar, D. (2017). Disruptions, Dilemmas and Paradoxes: Ethical Matter(s) in Design Research. Interacting with Computers, 29(1), 19.

Purpose. (n.d.). Retrieved from http://irsi.aboriginal.ubc.ca/purpose/

Redmond, M. (2010). Safe space oddity: Revisiting critical pedagogy. Journal of Teaching in Social Work, 30(1), 152-163.

The Roestone Collective. (2014). Safe space: Towards a reconceptualization. Antipode, 46(5), 1346-1365.

Rossiter, D., \& Burke Wood, P. (2017). The politics of Aboriginal title in British Columbia: From the Referendum to the Truth and Reconciliation Commission. Retrieved from https://viurrspace.ca/handle/10613/4980

satifice. (2015, September 10). It's time to get personal, dirty, and downright nasty [Tumblr]. Retrieved from https://satifice.tumblr.com/post/128776550132/its-time-to-getpersonal-dirty-and-downright

School of Library, Archival and Information Studies. (1998). First Nations curriculum concentration pamphlet. University of British Columbia [Marketing Material].

Sensoy, Ö., \& DiAngelo, R. (2014). Respect differences? Challenging the common guidelines in social justice education. Democracy and Education, 22(2).

Terry, G., Hayfield, N., Clarke, V., \& Braun, V. (2017). Thematic analysis. In C. Willig \& W. R. Stainton (Eds.), The SAGE Handbook of Qualitative Research in Psychology (17-37). London: Sage Publications Ltd.

Truth and Reconciliation Commission of Canada. (2015). Honouring the truth, reconciling for the future: Summary of the final report of the Truth and Reconciliation Commission of Canada. Winnipeg: Truth and Reconciliation Commission of Canada. 
Tsukada, H., \& Perreault, A. (2016). Complicating how classroom climate works: Advancing the framework. Transformative Dialogues: Teaching \& Learning Journal, 9(2), 1-18.

UBC Aboriginal Strategic Plan Development Working Group. (2008). UBC Aboriginal strategic plan. Retrieved from http://aboriginal.ubc.ca/files/2013/01/ASP-FinalComplete.pdf

Ward, Kevin. (2014, September 12). Looking Back to 2013.... Indian Residential School Initiative Retrieved from http://irsi.aboriginal.ubc.ca/2014/09/12/looking-back-one-year/

Warrell, M. (2014, February 3). Learn, unlearn and relearn: How to stay current and get ahead. Forbes. Retrieved from https://www.forbes.com/sites/margiewarrell/2014/02/03/learn-unlearn-andrelearn/\#3a4d6319676f

Woolman, J. (2017, September 29). Acceptance speech. Presented at the iSchool Awards Gala, University of British Columbia.

Young, I. M. (1990). Justice and the politics of difference (2011 ed.). Princeton, NJ: Princeton University Press.

Lisa P. Nathan (lisa.nathan@ubc.ca) is Associate Professor and Coordinator of the First Nations Curriculum Concentration at the University of British Columbia's iSchool (School of Library, Archival and Information Studies). Through a range of collaborative projects she strives to (re)imagine and (re)design information practices and ways of managing information in order to address long-term societal challenges (e.g., decolonization, social justice, environmental resilience).

Amy Perreault (amy.perreault@ubc.ca) is the Strategist, Indigenous Initiatives at the Centre for Teaching, Learning and Technology (CTLT) at the University of British Columbia on the traditional and unceded territory of the Musqueam people. She works with staff, faculty groups, and training programs for teaching assistants, new faculty, and administrators, to support the development of a higher standard of professionalism in conducting discussions of Indigenous initiatives and other contentious social issues in curricular settings. Amy is a codeveloper and researcher for the educational resource What I Learned in Class Today: Aboriginal Issues in the Classroom and manages the development of Indigenous Foundations. Work on these projects, as well as her own experience as an Indigenous student at UBC, clearly identify the complexities and challenges of classroom conversations involving contentious cross-cultural discussions, and in specific discourse around Indigenous curriculum. 